\title{
DISPERSÃO DE ARGILA EM MICROAGREGADOS DE SOLO INCUBADO COM CALCÁRIO(1)
}

\author{
Silvio Tulio Spera ${ }^{(2)}$, José Eloir Denardin ${ }^{(3)}$, Pedro Alexandre Varella Escosteguy ${ }^{(4)}$, \\ Henrique Pereira dos Santos ${ }^{(3)}$ \& Enrique Alberto Figueroa ${ }^{(5)}$
}

\begin{abstract}
RESUMO
A compactação do solo restringe o rendimento de culturas de grãos. Dentre outros fatores, a calagem pode favorecer a dispersão de microagregados e a formação de camadas compactadas. $O$ objetivo deste trabalho foi avaliar os efeitos do calcário e da esterilização em atributos físicos e químicos do solo relacionados com a compactação do solo. $O$ experimento foi efetuado em colunas de PVC, em casa de vegetação, durante 18 meses. Amostras esterilizadas e não esterilizadas de um Latossolo Vermelho distrófico foram incubadas com doses equivalentes a $\mathbf{0}$, $1,9,3,8,5,7,7,6$ e 15,2 $\mathrm{Mg} \mathrm{ha}^{-1}$. Após 18 meses, foram avaliados a macro e microporosidade, a densidade do solo, teor de argila dispersa, a condutividade hidráulica saturada, o pH e os teores de Al, Ca e Mg trocáveis e de matéria orgânica do solo. A calagem aumentou a densidade do solo, o teor de argila dispersa em água,

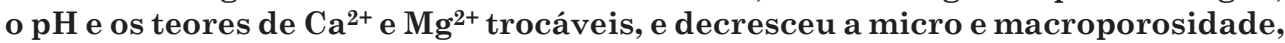
a condutividade hidráulica saturada, os teores de matéria orgânica e de Al trocável. $\mathrm{O}$ aumento de pH e a redução da condutividade hidráulica saturada foram maiores no solo esterilizado. Os efeitos da calagem foram mais pronunciados na quantidade correspondente a $3,8 \mathrm{Mg} \mathrm{ha}^{-1}$. A esterilização aumentou o valor do $\mathrm{pH}$ em água e reduziu os teores de matéria orgânica e de $\mathrm{Ca}^{2+}$, além da condutividade hidráulica saturada. A dispersão de microagregados pela calagem pode, em parte, contribuir para a compactação do solo.
\end{abstract}

Termos de indexação: Estabilidade de agregados, latossolo, iluviação, atributos químicos, atributos físicos.

(1) Trabalho apresentado no XXXI Congresso Brasileiro de Ciência do Solo, 2007 (Gramado, RS).

(2) Pesquisador, Embrapa Trigo, Doutorando em Agronomia, Universidade de Passo Fundo, BR 285 km 291, Caixa Postal 611, CEP 99001-970. E-mail: spera@enpt.embrapa.br

(3) Pesquisador, Embrapa Trigo, BR 285 km 294, Caixa Postal 451, CEP 99001-970. E-mails: denardin@cnpt.embrapa.br; hpsantos@cnpt.embrapa.br

(4) Professor, Universidade de Passo Fundo. E-mail: escosteguy@upf.br

(5) Pesquisador, INTA Mercedes, Argentina, Mestrando em Agronomia, Universidade de Passo Fundo. E-mail: efigueroa@correo.inta.gov.ar 


\title{
SUMMARY: CLAY DISPERSIONINMICROAGGREGATES OF SOIL INCUBATED WITH LIMESTONE
}

\begin{abstract}
Soil compaction limits grain yields. Among others factors, soil amendment with agricultural lime can contribute to micro-aggregate dispersion and the formation of compacted layers. The objective of this study was to evaluate the effect of lime on soil physical attributes related to soil compaction. The experiment was carried out in PVC columns, in a glass house, during 18 months. Sterilized and non-sterilized samples of a dystrophic Red Latosol (Hapludox) were incubated with 0, 1.9, 3.8, 5.7, 7.6 and 15.2 Mg ha-1. After the incubation period, the micro and macro porosity, soil density, clay dispersion, hydraulic conductivity and concentration of exchangeable $\mathrm{Al}, \mathrm{Ca}$ and $\mathrm{Mg}$ and soil organic matter were evaluated. Soil density, clay dispersion, $\mathrm{pH}$ and $\mathrm{Ca}$ and $\mathrm{Mg}$ concentration increased with lime application, while macro porosity, hydraulic conductivity, soil organic matter, and $\mathrm{Al}$ decreased. The increase of $\mathrm{pH}$ and hydraulic conductivity were higher in the sterilized soil. Liming effects were more evident at a rate of $3.8 \mathrm{Mg} \mathrm{ha}^{-1}$. Soil sterilization increased the $\mathrm{pH}$ value and decreased the organic matter content and $\mathrm{Ca}$, besides the hydraulic conductivity. Micro- aggregate dispersion in limed soils can, at least partially, contribute to soil compaction.
\end{abstract}

Index terms: Aggregate stability, oxisol, clay iluviation, soil chemical attributes, physical attributes.

\section{INTRODUÇÃO}

No sul do Brasil, o cultivo de grãos, em condições de sequeiro, predomina em solos originados de basalto, profundos, bem drenados, com baixo teor de argila dispersa em água e teor médio de matéria orgânica (25 a $40 \mathrm{~g} \mathrm{dm}^{-3}$ ). Esses solos contêm, ainda, baixos teores de $\mathrm{P}, \mathrm{Ca}$ e $\mathrm{Mg}$, elevada acidez e teor de Al trocável (Brasil, 1973), o que limita o cultivo de grãos. Contudo, esses solos são considerados aptos ao desenvolvimento dessas culturas, considerando os atributos físicos: porosidade, permeabilidade, estrutura, textura e consistência (Streck et al., 2002), e a correção da acidez com calcário (Wiethölter, 2000).

A partir da década de 1950, os solos do sul do Brasil foram cultivados com grãos, sendo mobilizados de forma intensiva para incorporação de fertilizantes e corretivos. Essa interferência antrópica melhorou a qualidade química dos solos; entretanto, alterou a qualidade física (Denardin et al., 2001). Isso está associado à degradação da estrutura do solo, na camada arável, percebida pelo aumento na resistência à penetração, na densidade e na erosão, no decréscimo da macroporosidade, da porosidade total e da taxa de infiltração de água, além de alterações morfológicas do sistema radicular das plantas cultivadas (Tormena et al., 1998). A partir da década de 1990, o cultivo de grãos no sul do Brasil passou a ser, predominantemente, em solos manejados com sistema plantio direto. A introdução desse sistema reduziu expressivamente a perda de solo por erosão; no entanto, não evitou a compactação do solo, sendo essa condição associada à limitação da produtividade pelos produtores rurais e pesquisadores (Kochhann et al., 2000).
A compactação do solo em sistema plantio direto manifesta-se principalmente na camada de $7-20 \mathrm{~cm}$ de profundidade (Kochhann et al., 2000). Isso sugere que a compactação seja remanescente da mobilização intensiva do solo, praticada antes da adoção do sistema plantio direto. Além disso, esse processo de transformação estrutural do solo pode também ter sido, em parte, condicionado pela calagem.

A dispersão das partículas coloidais do solo está relacionada com a interação das cargas elétricas na superfície e pode ser gerada por substituição isomórfica (permanentes) ou por dissociação de radicais (variáveis). As variáveis, predominantes em Latossolos, dependem de propriedades químicas do solo: pH e concentração eletrolítica da solução do solo (Azevedo \& Bonumá, 2004). Os Latossolos apresentam agregação primária na forma de pequenos grânulos, muito estáveis e resistentes em estado natural.

A neutralização do Al trocável, íon que estabiliza a estrutura do solo, e a elevação do $\mathrm{pH}$ do solo, que, na faixa de $\mathrm{pH}$ menor que 7,0 tem ação dispersante (Jucksch, 1987; Pavan \& Roth, 1992), contribuem para a dispersão do solo em partículas unitárias. Esse efeito também foi verificado com os fertilizantes de elevado índice salino (Carvalho Jr. et al., 1998). A estabilidade dos agregados do solo depende da textura, mineralogia (óxidos e silicatos), teores e tipos de cátions, pH da matéria orgânica (Ferreira et al., 1999; Meurer, 2006). Esses fatores são determinantes da espessura da dupla camada difusa, que é importante e fundamental fator que influencia a dispersão e floculação de partículas. A espessura da dupla camada difusa é alterada pela concentração e tipo de eletrólitos (íons $\mathrm{Na}, \mathrm{K}$, etc.). Cátions com alto grau de hidratação formam complexos de esfera externa e aumentam a 
distância entre as partículas; desse modo, as forças de atração de curto alcance não se manifestam e o sistema dispersa (Meurer, 2006).

Em solos com os microagregados dispersos, a água de percolação promove a eluviação das partículas de argila dispersa e o rearranjo dessas partículas altera a matriz sólida do solo (Torres \& Saraiva, 1999; Kochhann et al., 2000). Assim, a porosidade natural passa a ser obstruída pelas partículas de argila iluviadas, elevando a densidade do solo. Dessa forma, a perda de estabilidade dos macroagregados e o fracionamento em microagregados, bem como a conseqüente iluviação da argila, desenvolvem a camada superficial dispersa, com estrutura maciça de grãos simples. Simultaneamente a esses processos, as forças mecânicas resultantes do tráfego de máquinas agrícolas e do pisoteio de animais promovem aproximação dos microagregados e das partículas unitárias dispersas, elevando a densidade do solo. Em decorrência dessa compactação, muito comum em solos sob o sistema plantio direto, este sistema poderá não se viabilizar de forma ininterrupta (Klein \& Boller, 1995; Denardin et al., 2001; Câmara \& Klein, 2005).

O objetivo deste trabalho foi avaliar os efeitos do calcário e da esterilização em atributos físicos e químicos do solo relacionados com a compactação e dispersão de argila de um Latossolo Vermelho do Rio Grande do Sul, manejado em sistema plantio direto.

\section{MATERIAL E MÉTODOS}

O experimento foi efetuado em casa de vegetação na Embrapa Trigo, em Passo Fundo, RS, de fevereiro de 2002 a agosto de 2003. Para tanto, tubos de PVC, de $25 \mathrm{~cm}$ de altura e $10 \mathrm{~cm}$ de diâmetro, foram preenchidos com $20 \mathrm{~cm}$ de solo. $\mathrm{O}$ solo utilizado foi um Latossolo Vermelho distrófico típico da classe textural argila, sendo coletado na camada de $0-20 \mathrm{~cm}$. Esse solo encontrava-se em uma área sob campo nativo, sem antecedentes de uso agrícola ou pecuário. As características químicas da amostra utilizada, antes do experimento, eram: $\mathrm{pH}$ em água, 4,9; índice SMP, 5,1; P e K trocável, respectivamente, 6 e $23 \mathrm{mg} \mathrm{dm}^{-3}$; Ca, Mg e Al trocáveis, 1,0; 0,6 e 1,9 $\mathrm{cmol}_{\mathrm{c}} \mathrm{dm}^{-3}$, respectivamente; e matéria orgânica, $31,0 \mathrm{~g} \mathrm{dm}^{-3}$. Esses atributos foram obtidos com os métodos analíticos descritos em Tedesco et al. (1995).

Cerca de $1,7 \mathrm{~kg}$ de TFSA foi utilizado em cada unidade experimental, o que determinou predomínio de microagregados. Na abertura inferior dessas colunas, foi colocada uma tela de material plástico usada na construção civil como isolante em concretagem, com diâmetro de malha de $0,05 \mathrm{~mm}$, para permitir a livre saída de água. Na abertura superior da coluna, um disco de tela de nylon e uma camada de algodão, de um centímetro de espessura, foi mantida com o objetivo de evitar o turbilhonamento da água aplicada. A densidade do solo, no início do experimento, foi $1,12 \mathrm{Mg} \mathrm{m}^{-3}$, sendo ajustada de forma homogênea ao longo da coluna de PVC.

$\mathrm{O}$ experimento foi um bifatorial $(2 \times 6)$, em delineamento completamente casualizado com oito repetições. Metade das colunas foi esterilizada (E) com solução de formaldeído 5 \% (Alcântara, 1995), para isolar o efeito da microbiota na agregação do solo, e metade não foi esterilizada (NE). A solução de formaldeído foi utilizada, uma vez que não alterou a estabilidade dos agregados do solo em teste preliminar.

Em cada condição de esterilização, foram utilizadas oito repetições. Foram adicionadas seis doses de calcário correspondentes a: 0, 1,9, 3,8, 5,7, 7,6 e 15,2 $\mathrm{Mg} \mathrm{ha}^{-1}$, correspondendo, respectivamente, a 0, 25, 50, 75, 100 e $200 \%$ da quantidade recomendada para elevar o $\mathrm{pH}$ em água a 6,0 (PRNT $100 \%$ ), conforme sugerido por CQFSRS/SC (2004). O PRNT do calcário usado foi $70 \%(\mathrm{PN}=85 \%$; ER = $63 \%)$, sendo esse corretivo tamisado junto com o solo em malha de $2,0 \mathrm{~mm}$.

As colunas de solo foram submetidas a regime de umedecimento e secagem para simular as condições naturais. Essas colunas, por apresentarem a abertura inferior parcialmente vedada por uma tela porosa, permitiam a livre saída da água percolada. Foram percolados $200 \mathrm{~mm}$ de água mensalmente, sendo esse volume dividido em cinco aplicações de $40 \mathrm{~mm}$, efetuadas a cada seis dias.

A supressão da atividade microbiana das amostras esterilizadas foi verificada com a contagem de microrganismos, em placas de Petri, sendo essa avaliação realizada sete vezes, conforme Vincent (1970). As colunas foram retiradas da casa de vegetação, 18 meses após a aplicação do calcário, para serem submetidas às análises físicas (densidade do solo, macroporosidade, microporosidade, condutividade hidráulica saturada, argila dispersa em água e grau de floculação) e químicas de solo (pH, Al trocável, matéria orgânica, $\mathrm{Ca}$ e Mg trocáveis).

A densidade do solo, a macroporosidade e a microporosidade foram avaliadas somente nas camadas de 0 - 5 e de $15-20 \mathrm{~cm}$ das colunas, tendo em vista o elevado risco de se perder a integridade estrutural das amostras em eventuais operações de corte e abertura do interior das colunas. As demais variáveis foram avaliadas na camada de $15-20 \mathrm{~cm}$, pois, nessa camada, ocorre a concentração de nutrientes lixiviados e de partículas de argila lessivadas. As demais camadas não foram analisadas por terem sido muito alteradas ou pela dificuldade em mantê-las íntegras após a o fim do experimento.

Os procedimentos e métodos utilizados nas avaliações dos atributos físicos foram os descritos em Embrapa (1997), enquanto nas avaliações dos atributos químicos foram os descritos em Tedesco et al. (1995). Exceto as avaliações da densidade do solo, porosidade total, argila total, argila dispersa em água, as demais avaliações foram efetuadas por ocasião da montagem 
da coluna, em toda a amostra, e, após a conclusão do experimento, na camada de $15-20 \mathrm{~cm}$. As avaliações de condutividade hidráulica saturada, macroporosidade, microporosidade foram efetuadas somente na ocasião do desmonte das colunas.

Para avaliação estatística dos resultados obtidos, usou-se a análise de variância (efeitos da esterilização e do calcário) e análise de regressão (doses de calcário), sendo utilizado o programa estatístico SAS (SAS, 2003).

\section{RESULTADOS E DISCUSSÃO}

Os atributos físicos e químicos avaliados não variaram $(p<0,05)$ com a interação entre doses de calcário e a condição de esterilização do solo. No entanto, os atributos físicos: densidade do solo, micro e macroporosidade, condutividade hidráulica saturada, argila dispersa em água e grau de floculação; e químicos: $\mathrm{pH}, \mathrm{Al}^{3+}, \mathrm{Ca}^{2+}, \mathrm{Ca}^{2+}+\mathrm{Mg}^{2+}$ e matéria orgânica do solo variaram de acordo com a dose de calcário, quando esse fator foi avaliado de forma isolada. Da mesma forma, o efeito isolado da esterilização do solo influenciou os valores da condutividade hidráulica saturada e do pH, além dos teores de $\mathrm{Al}^{3+}$ e de matéria orgânica do solo.

Para densidade do solo, micro e macroporosidade, avaliadas em duas profundidades, foram observadas diferenças entre as duas profundidades estudadas.

As doses de calcário aplicadas elevaram a densidade do solo e decresceram a macroporosidade das colunas somente na camada de $15-20 \mathrm{~cm}$ (Figuras 1). A densidade do solo variou de 1,12 a 1,32-1,35 $\mathrm{Mg} \mathrm{m}^{-3}$ na média das amostras não esterilizadas e esterilizadas, após 18 meses da aplicação do calcário.

O acréscimo da densidade do solo e da microporosidade (Figura 1a, b) e o decréscimo da macroporosidade (Figura 1c), observados na camada de 15-20 cm, podem ser considerados indicativos de alterações estruturais decorrentes do efeito do calcário na compactação de solo. Isso pode ser assumido, por se considerar o período de 18 meses suficiente para se observar reorganização estrutural no solo (Jucksch, 1987; Chaves, 1995), como observado neste experimento. Os menores valores de macroporosidade, observados nas doses de

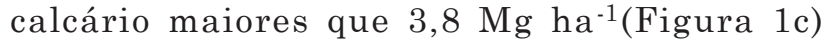
sugerem que as alterações causadas pela calagem podem favorecer a redução de macroporos do solo (Azevedo \& Bonumá, 2004).

Os resultados (Figura 1) mostram que o efeito da calagem sobre a densidade, macro e microporosidade do solo estabiliza-se na dose $7,6 \mathrm{Mg} \mathrm{ha}^{-1}$, não alterando com a aplicação do dobro dessa quantidade. Isso indica que esses efeitos ocorrem até o valor de $\mathrm{pH} 6,0$, pois a dose de 7,6 $\mathrm{Mg} \mathrm{ha}^{-1}$ corresponde à quantidade de calcário necessária para elevar o $\mathrm{pH}$ do solo utilizado a esse valor (CQFSRS/SC, 2004).

(a)

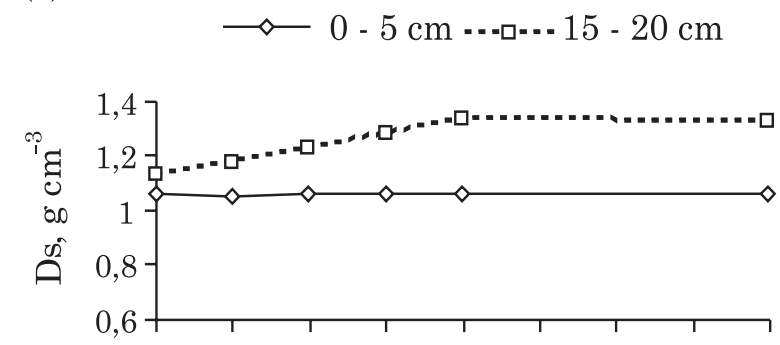

(b)

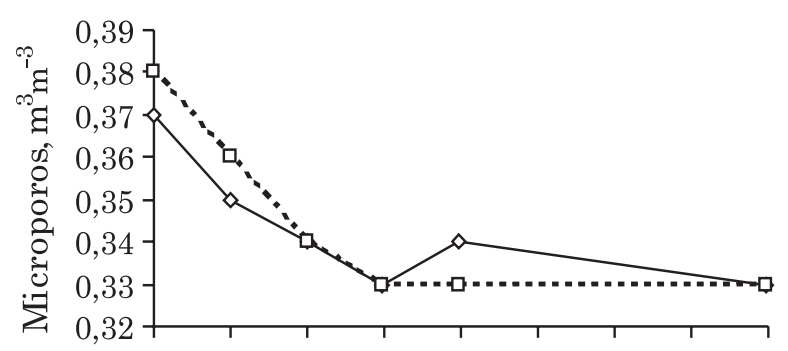

(c)

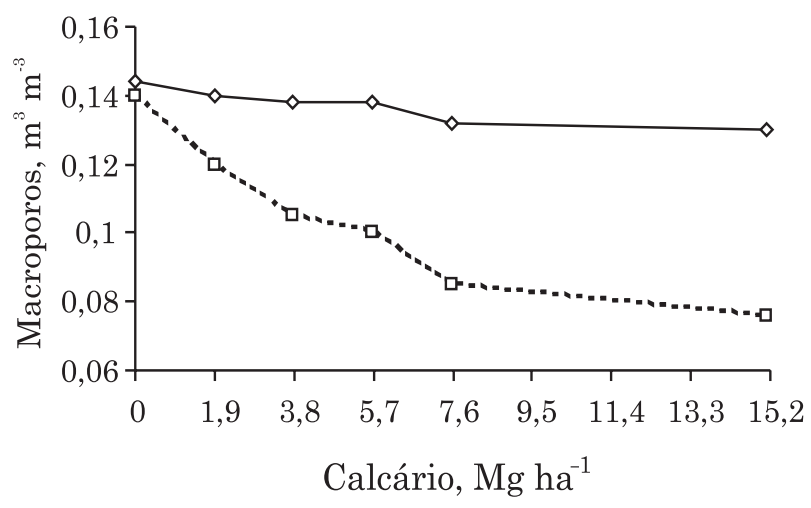

Figura 1. Valores de (a) densidade (Ds), (b) micro e (c) macroporosidade de duas camadas de solo incubado com doses de calcário.

Como observado com a densidade do solo (Figura 1a), houve aumento do conteúdo de argila dispersa em água, conforme a aplicação das doses de calcário (Figura 2a) sendo esse efeito somente observado na de camada 15-20 cm. Como não houve efeito simples, ou da interação com o calcário, da condição de esterilização do solo, a dispersão de argila pelo calcário foi decorrente de processos físico-químicos, sendo esses preponderantes em relação aos processos microbianos, o que está de acordo com o relato de Roth \& Pavan (1991), Pavan \& Roth (1992) e Azevedo \& Bonumá (2004). 
(a)

$$
\checkmark \text { Início - - - - - . Após } 18 \text { meses }
$$

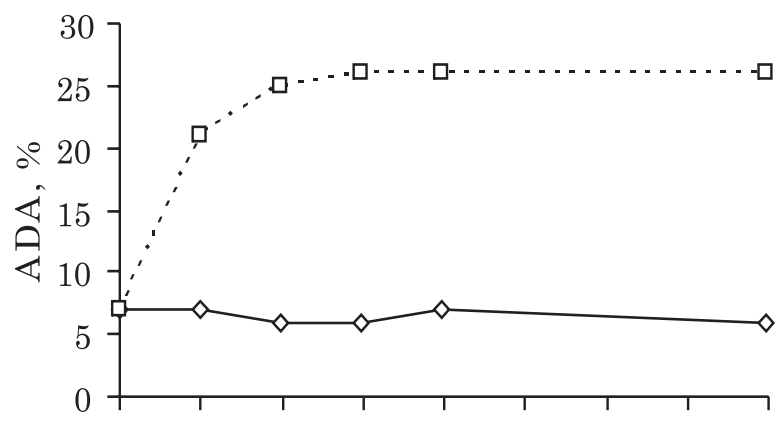

(b)

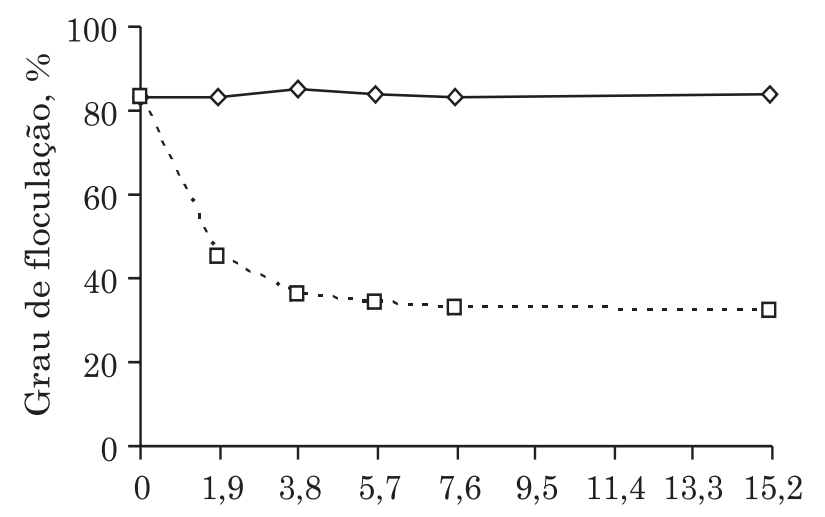

Calcário, $\mathrm{Mg} \mathrm{ha}^{-1}$

Figura 2. (a) Teores de argila dispersa em água (ADA) e (b) grau de floculação, na camada de 15 a 20 cm da coluna, no início e após 18 meses da incubação do solo com doses crescentes de calcário.

Na camada de $15-20 \mathrm{~cm}$, o conteúdo de argila dispersa em água do solo variou de $7 \%$, no solo sem calcário, a $22 \%$, com a incubação do equivalente a $1,9 \mathrm{Mg} \mathrm{ha}^{-1}$, sendo esse percentual próximo do obtido no tratamento $3,8 \mathrm{Mg} \mathrm{ha}^{-1}$, mantendo-se constante a partir dessa dose (Figura 2a).

Esse efeito pode contribuir para o início do processo de formação de camadas compactadas, verificadas em Latossolos brasileiros submetidos à calagem (Chaves, 1998; Kochhann et al., 2000; Denardin et al., 2001). A aplicação de calcário com poder de neutralização baixo, como no caso desse estudo, favoreceu, após 18 meses, a dispersão de argilas, cujo efeito foi crescente até à dose de $3,8 \mathrm{Mg} \mathrm{ha}^{-1}$ (PRNT $100 \%$ ). Nas doses maiores que $3,8 \mathrm{Mg} \mathrm{ha}^{-1}$, esse efeito estabilizou, o que pode estar associado à neutralização do $\mathrm{Al}^{3+}$ e à substituição desse cátion por $\mathrm{Ca}^{2+} \mathrm{e} \mathrm{Mg}^{2+}$ no complexo de troca (Figura 2a).
O grau de floculação acompanhou de modo inverso (Figura 2b) o que se observou com teor de argila dispersa em água, indicando que houve desestabilização dos agregados com a incubação do solo com calcário. No Planalto Médio do Rio Grande do Sul, predominam Latossolos cauliníticos com elevada contribuição de óxidos de $\mathrm{Fe}$ e $\mathrm{Al}$ (Brasil, 1973). Essa composição mineralógica favorece a dispersão de agregados quando da adição de ânions, principalmente, os carbonatos resultantes da dissolução do calcário. Conforme Morelli \& Ferreira (1987), os carbonatos e os fosfatos atuam como neutralizadores do efeito floculante dos cátions $\mathrm{Al}^{3+} \mathrm{e} \mathrm{H}^{+}$, com o conseqüente aumento do $\mathrm{pH}$ e das cargas negativas de óxidos de $\mathrm{Fe}$ e $\mathrm{Al}$ e da caulinita. Albuquerque et al. (2002), utilizando resíduos industriais alcalinos, também observaram redução na floculação de argilas em um Cambissolo Húmico caulinítico.

A condutividade hidráulica em solo saturado decresceu com o aumento da dose de calcário. Esse efeito está relacionado com a obstrução dos poros, principalmente dos macroporos (Figura 1c). Isso foi devido à dispersão de argilas favorecida pela calagem, sendo também verificado em outros trabalhos (Roth \& Pavan, 1991).

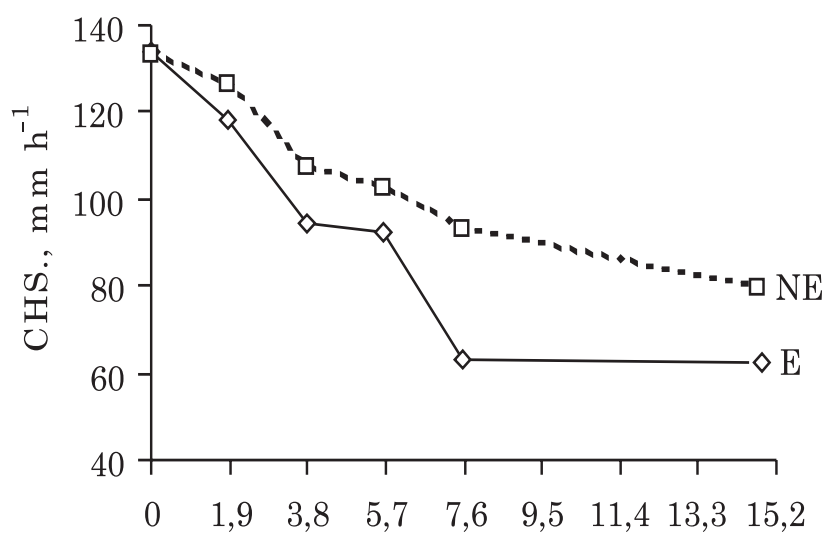

Calcário, $\mathrm{Mg} \mathrm{ha}^{-1}$

Figura 3. Condutividade hidráulica saturada (CHS) do solo esterilizado (E) e não esterilizado (NE), de acordo com as doses crescentes de calcário.

Os valores de $\mathrm{pH}$ aumentaram e o teor de $\mathrm{Al}^{3+}$ decresceu, com o acréscimo das doses de calcário até à completa neutralização da acidez (Figura 4a e 4b). Foram, ainda, constatadas diferenças nos valores desses atributos entre o solo esterilizado e não esterilizado. A solução de formaldeído aumentou o valor do $\mathrm{pH}$ e, conseqüentemente, reduziu o teor de $\mathrm{Al}^{3+}$, embora não tenha proporcionado alterações nos atributos físicos. Os valores de $\mathrm{pH}$ observados na dose de 1,9 $\mathrm{Mg} \mathrm{ha}^{-1}$ (PRNT $100 \%$ ) foram maiores que 6,0 , indicando que o efeito do calcário foi maior do que o recomendado para as condições de campo. Isso 
se deve, possivelmente, ao revolvimento e homogeneização intensiva do calcário com o solo, quando da montagem das colunas e da manutenção da umidade do solo no decorrer do experimento. Além dos efeitos observados sobre estes atributos químicos, esse aspecto deve ter favorecido a dispersão e eluviação de argila. Assim, solos com calagem excessiva devem apresentar maior potencial de dispersão de argilas e, portanto, condições mais propícias à compactação.

(a)

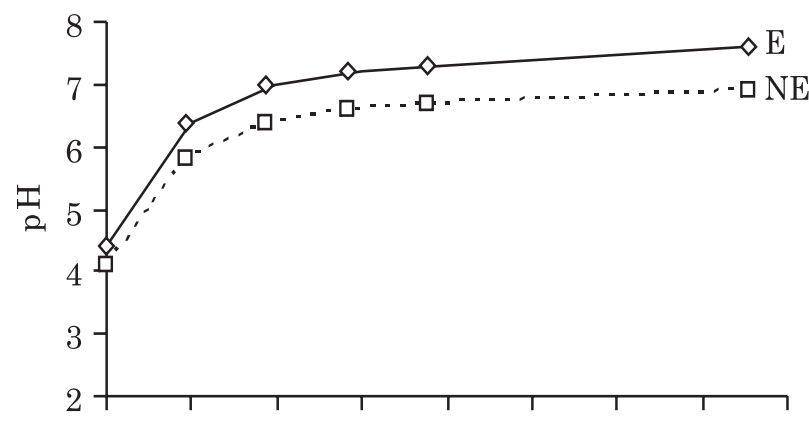

(b)

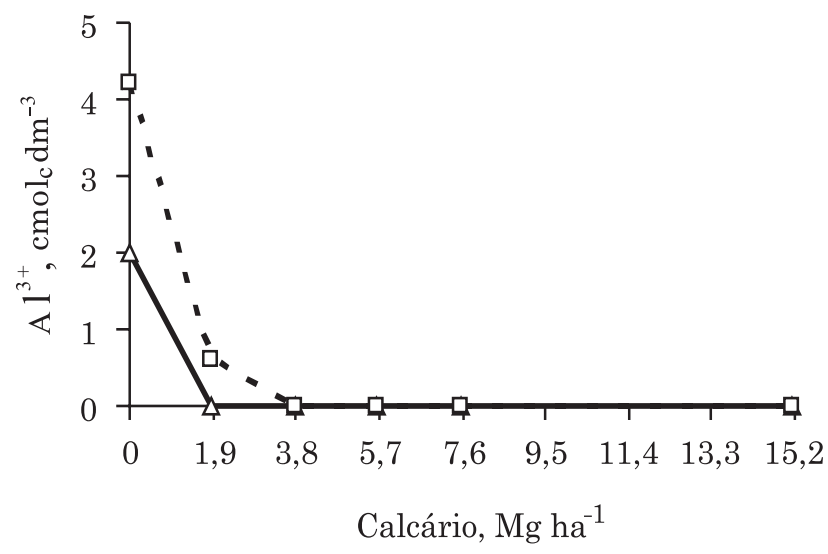

Figura 4. Valor de pH (a) e teor de alumínio trocável (b), em colunas de solo esterilizadas (E) e não esterilizadas (NE), na camada 15 $20 \mathrm{~cm}$, de acordo com as doses crescentes de calcário.

Esterilizar o solo com formaldeído provoca mortalidade da microbiota (Alcântara, 1995), o que poderá reduzir a produção de ácidos orgânicos, resultantes do metabolismo microbiano, e a decomposição da matéria orgânica (Moreira \& Siqueira, 2006). Nesse experimento, observou-se maior teor de matéria orgânica do solo nas colunas esterilizadas (Figura 5). Esse efeito pode ser resultado da adição de biomassa de microrganismos mortos e da redução na decomposição da matéria orgânica decorrente da inibição de microrganismos heterotróficos, decompositores de matéria orgânica.

Os teores de $\mathrm{Ca}^{2+}$ e de $\mathrm{Mg}^{2+}$ do solo não diferiram entre as condições de esterilização, mas aumentaram com a adição de calcário (Figura 6 ). Por outro lado, o decréscimo do teor de $\mathrm{Mg}^{2+}$, observado nas maiores doses de calcário, revela que o Mg trocável foi deslocado para a solução, pelo Ca adicionado, sendo lixiviado pela água de irrigação (Figura 6).

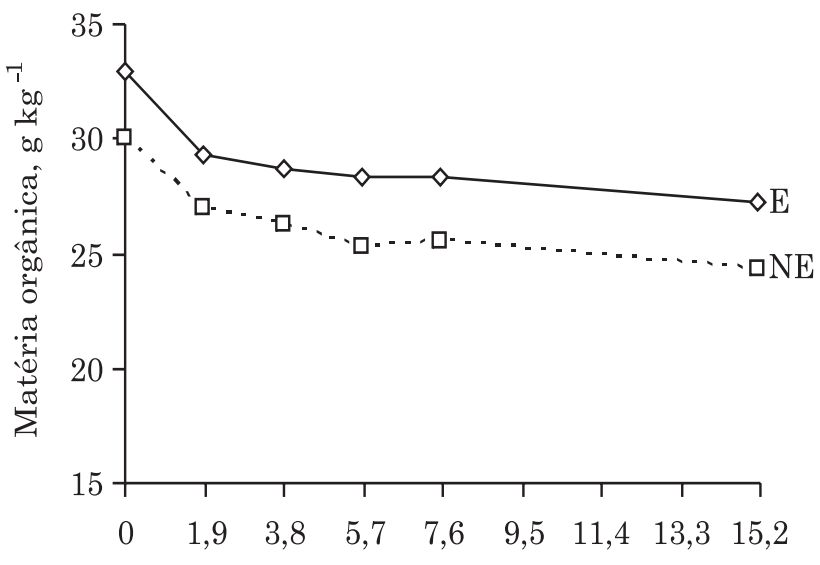

Calcário, $\mathrm{Mg}_{\mathrm{ha}}{ }^{-1}$

Figura 5. Teor de matéria orgânica do solo, em colunas de solo esterilizadas (E) e não esterilizadas (NE), de acordo com as doses crescentes de calcário.

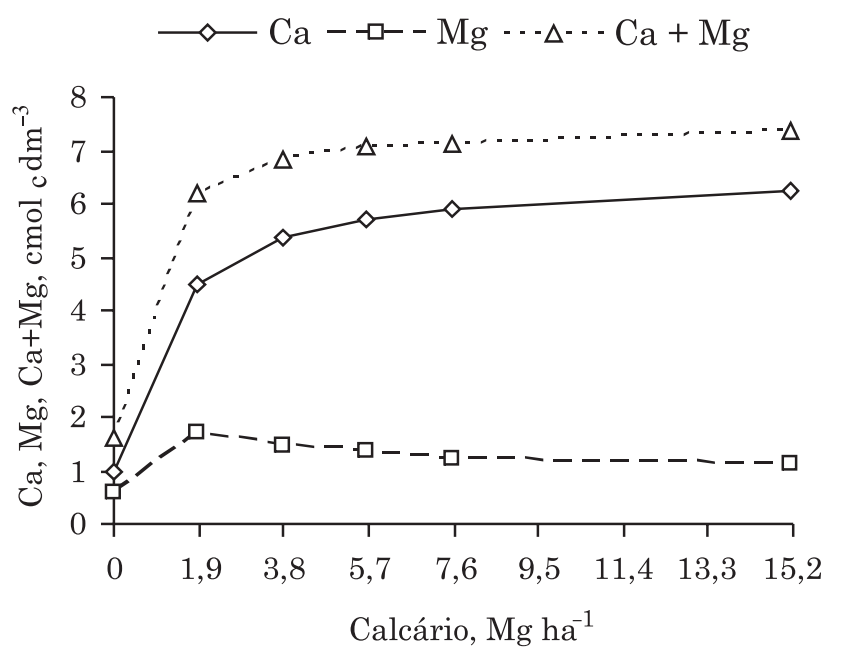

Figura 6. Teores de cálcio, magnésio e cálcio+ magnésio trocáveis, na camada $15-20 \mathrm{~cm}$ da coluna, de acordo com as doses crescentes de calcário.

Os resultados obtidos indicam que os processos envolvidos na gênese das camadas compactadas podem estar relacionados com a dispersão de argilas 
resultante da aplicação de calcário, além de fatores pedogenéticos e os relacionados com uso e manejo de solo, já mensurados por outros autores (Silva \& Cabeda, 2004; Silva et al., 2004; Lima et al., 2006).

A dispersão de argilas (Figura 2a) aumentou com a calagem, pois a correção do $\mathrm{pH}$ do solo precipita o $\mathrm{Al}^{3+}$ (Figuras 4a, b), tornando-o insolúvel. Esse cátion, por ser trivalente, atua como um contra-íon na solução do solo (Meurer, 2006) e, quando ocorre elevação da concentração de eletrólitos, como em solos calcariados, por exemplo, ocorre diminuição da espessura da dupla camada elétrica difusa, junto à superfície das partículas coloidais. Nessa condição, a agregação das partículas de cargas negativas é favorecida, considerando o predomínio de pontes catiônicas e de outras forças atrativas (McBride, 1989). Com a calagem, o Al trocável (trivalente) é substituído pelo Ca e o $\mathrm{Mg}$ (divalentes), adicionados com esse corretivo, o que atenua o efeito dispersante dos carbonatos. Isso pode ser confirmado quando se comparam os efeitos do calcário na dispersão de argila com os teores de $\mathrm{Ca}^{2+} \mathrm{e} \mathrm{Mg}^{2+}$ do solo das colunas (Figuras 2a e 6). As curvas representativas desses efeitos seguiram a mesma tendência, ou seja, o teor de argila dispersa cresceu expressivamente até à dose de $3,8 \mathrm{Mg} \mathrm{ha}^{-1}$, estabilizando a partir de $5,7 \mathrm{Mg} \mathrm{ha}^{-1}$, sendo isso também observado com a soma dos teores de $\mathrm{Ca}$ e $\mathrm{Mg}$ trocáveis (Figura 6).

Uma vez que, neste estudo, só foi utilizada amostra de solo da fração TFSA, não foi possível avaliar a estabilidade de agregados em água. Após 18 meses, não se constatou a formação de agregados estáveis em água maiores que $4,76 \mathrm{~mm}$, em nenhum dos tratamentos. Por outro lado, a formação de uma camada levemente adensada no fundo das colunas, identificada visualmente e por manipulação, principalmente na dose maior que $5,7 \mathrm{Mg} \mathrm{ha}^{-1}$, indicou que houve rearranjo de argila dispersa em uma camada laminar de menor condutividade hidráulica.

Os resultados de análises físicas mostraram que o aumento da densidade do solo (Figura 1a), da microporosidade (Figura 1b) e da argila dispersa em água (Figura 2a), bem como a redução da macroporosidade (Figura 1c) e da condutividade hidráulica saturada (Figura 3), não foram proporcionais ao incremento da dose de calcário. Os valores desses atributos estabilizaram a partir de determinada dose de calcário, mesmo na dose mais elevada. Os Latossolos cauliníticos, como os da região do Planalto Médio do Rio Grande do Sul, apresentaram menor tendência à formação de microagregados, envolvendo o desenvolvimento de estrutura predominante na forma de blocos, originando solos mais densos e de menor porosidade e permeabilidade (Ferreira et al., 1999).

O preenchimento do espaço poroso com argila dispersa também apresentou um limite. Esse rearranjo estrutural foi determinado pela esfericidade das partículas unitárias e, num arranjo de partículas esféricas, um mínimo espaço entre as partículas deveria existir (Raghavan et al., 1990). A dispersão de argila mostrou-se dependente, dentre outros, do valor de $\mathrm{pH}$, da CTC, da espessura da partícula de argila, do teor de matéria orgânica e dos teores de óxidos de $\mathrm{Fe}$ e $\mathrm{Al}$ livres, havendo um valor máximo para o total de argila dispersa, em condições de solo agrícola (Assouline et al., 1997). O rearranjo das partículas de argila dispersa não pode, então, ocupar todo o espaço poroso. Isso permite concluir que a contribuição do calcário para a dispersão da argila e a conseqüente formação de camadas compactadas são devidas ao rearranjo da argila lessivada e apresentam um valor-limite, ou seja, a dispersão ocorre provavelmente apenas na primeira calagem adicionada ao solo, enquato o rearranjo das partículas não ocupa todo o espaço poroso da camada iluviada. Assim, o efeito da calagem na dispersão de microagregados e a posterior compactação do solo podem ser relevantes na primeira correção do solo. Considerando que os solos manejados sob sistema plantio direto, geralmente, já haviam recebido calcário antes da adoção desse sistema, é pouco provável que a calagem venha a ser o principal fator de compactação do solo.

\section{CONCLUSÕES}

1. A aplicação de calcário aumentou a dispersão de microagregados. Esse efeito foi crescente até à incubação de $50 \%\left(3,8 \mathrm{Mg} \mathrm{ha}^{-1}\right)$ da dose recomendada para elevar o $\mathrm{pH}$ em água a 6,0 e não variou com a esterilização do solo.

2. A esterilização do solo não promoveu alteração nos valores dos atributos físicos do solo, exceto da condutividade hidráulica saturada, mas aumentou o valor do $\mathrm{pH}$ e o teor de $\mathrm{Ca}^{2+}$ e diminuiu os teores de $\mathrm{Al}$ trocável e da matéria orgânica do solo.

\section{LITERATURA CITADA}

ALBUQUERQUE, J.A.; ARGENTON, J.; FONTANA, E.C.; COSTA, F.S. \& RECH, T.D. Propriedades físicas e químicas de solos incubados com resíduo alcalino da indústria de celulose. R. Bras. Ci. Solo, 26:1.065-1.073, 2002.

ALCÂNTARA, R.M.C.M. Propriedades químicas e bioquímicas e suas inter-relações em solos sob vegetação de mata e campo adjacentes. Lavras, Universidade Federal de Lavras, 1995. 84p. (Tese de Mestrado)

ASSOULINE, S.; TAVARES FILHO, J. \& TESSIER, D. Effect of compaction on soil physical and hydraulic properties: Experimental results and modeling. Soil Sci. Soc. Am. J., 61:390-398, 1997.

AZEVEDO, A.C. \& BONUMÁ, A.S. Partículas coloidais, dispersão e agregação em Latossolos. R. Bras. Ci. Solo, 34:609-617, 2004. 
BRASIL. Ministério da Agricultura. DNPA. DPP. Levantamento de reconhecimento dos solos do Estado do Rio Grande do Sul. Recife, 1973. 431p. (Boletim Técnico, 30)

CÂMARA, R.K. \& KLEIN, V.A. Escarificação em plantio direto como técnica de conservação do solo e da água. R. Bras. Ci. Solo, 29:789-796, 2005.

CARVALHO JR., I.A.; FONTES, L.E.F. \& COSTA, L.F. Modificações causadas pelo uso e a formação de camadas compactadas e, ou, adensadas em um Latossolo VermelhoEscuro textura média, na região do Cerrado. R. Bras. Ci. Solo, 22:505-514, 1998.

CHAVES, L.H.G. Efeito do carbonato de cálcio em propriedades eletroquímicas e na dispersão de argila de um latossolo. In: CONGRESSO BRASILEIRO DE CIÊNCIA DO SOLO, 25., Viçosa, MG, 1995. Resumos expandidos. Viçosa, MG, Universidade Federal de Viçosa, 1995. v.1. p.348-349.

COMISSÃO DE QUIMICA E FERTILIDADE DO SOLO . CQFSRS/SC. Manual de adubação e de calagem para os estados do Rio Grande do Sul e Santa Catarina. 10.ed. Porto Alegre, Sociedade Brasileira de Ciência do Solo/ Núcleo Regional Sul, 2004. 400p.

DENARDIN, J.E.; KOCHHANN, R.A. \& DENARDIN, N.D. Calagem compacta solos? Fatos e hipóteses. In: SIMPÓSIO ROTAÇÃO SOJA MILHO NO PLANTIO DIRETO, 2., Piracicaba, 2001. Anais. Piracicaba, FEALQ 2001. 9p. CD-ROM.

EMPRESA BRASILEIRA DE PESQUISA AGROPECUÁRIA . EMBRAPA. Centro Nacional de Pesquisa de Solos. Manual de métodos de análises de solo. 2.ed. Rio de Janeiro, 1997. 212p.

FERREIRA, M.M.; FERNANDES, B. \& CURI, N. Mineralogia da fração argila e estrutura de Latossolos da região Sudeste do Brasil. R. Bras. Ci. Solo, 23:507-514, 1999.

JUCKSCH, I. Calagem e dispersão de argila em amostra de um Latossolo Vermelho-Escuro. Viçosa, MG, Universidade Federal de Viçosa, 1987. 37p. (Tese de Mestrado)

KLEIN, V.A. \& BOLLER, W. Avaliação de diferentes manejos de solos e métodos de semeadura em área sob sistema de plantio direto. Ci. Rural, 25:395-398. 1995.

KOCHHANN, R.A.; DENARDIN, J.E. \& BERTON, A.L Compactação e descompactação de solos. Passo Fundo, Embrapa Trigo, 2000. 20p. (Embrapa Trigo. Documentos, 19)

LIMA, C.L.R.; REINERT, D.J.; REICHERT, J.M. \& SUZUKI, E.A.S. Compressibilidade de um Argissolo sob sistema plantio direto escarificado e compactado. Ci. Rural, 36:1765-1772, 2006

McBRIDE, M.B. Surface chemistry of soil minerals. In: DIXON, J.B. \& WEED, S.B. Minerals in soil environments. 2.ed. Madison, Soil Science Society of America, 1989. p.35-88. (Series, 1).
MEURER, E.J. Fundamentos de química do solo. 3.ed. Porto Alegre, Evangraf, 2006. 285p.

MOREIRA, F.M.S. \& SIQUEIRA, J.O. Microbiologia e bioquímica do solo. 2.ed. Lavras, Universidade Federal de Lavras, 2006. 729p.

MORELLI, M. \& FERREIRA, E.B. Efeito do carbonato de cálcio e do fosfato diamônico em propriedades eletroquímicas e físicas de um Latossolo. R. Bras. Ci. Solo, 11:1-6, 1987.

PAVAN, M.A. \& ROTH, C.H. Effect of lime and gypsum on chemical composition of runoff and leachate from samples of a Brazilian Oxisol. Ci Cultura, 44:391-394, 1992.

RAGHAVAN, G.S.V.; ALVO, P. \& McKYES, E. Soil compaction in agriculture: A view toward managing the problem. Adv. Soil Sci., 11:1-35, 1990.

ROTH, C.H. \& PAVAN, M.A. Effects of lime and gypsum on clay dispersion and infiltration in samples of a Brazilian Oxisol. Geoderma, 48:351-361, 1991.

SAS Institute. SAS System for Microsoft Windows, version 8.2. Cary, 2003

SILVA, A.J.N. \& CABEDA, M.S.V. Compactação e compressibilidade do solo sob sistemas de manejo e níveis de umidade. R. Bras. Ci. Solo, 30:611-617, 2004.

SILVA, A.P.; IMHOFF, S. \& KAY, B. Plant response to mechanical resistance and air-filled porosity of soils under conventional and no-tillage system. Sci. Agric., 61:451456,2004

STRECK, E.V.; KÄMPF, N.; DALMOLIN, R.S.D.; KLAMT, E.; NASCIMENTO, P.S.C. \& SCHNEIDER, P. Solos do Rio Grande do Sul. Porto Alegre, Universidade Federal do Rio Grande do Sul, 2002. 130p.

TEDESCO, M.J.; GIANELLO, C.; BISSANI; C.A.; BOHNEN, H. \& VOLKWEISS, S.J. Análises de solo, plantas e outros materiais. 2.ed. Porto Alegre, Universidade Federal do Rio Grande do Sul, 1995. 174p. (Boletim Técnico, 5)

TORMENA, C.A.; ROLOFF, G. \& SA, J.C.M. Propriedades físicas de solos sob plantio direto influenciadas por calagem, preparo inicial e trafego. R. Bras. Ci. Solo, 22:301309, 1998.

TORRES, E. \& SARAIVA, O.F. Camadas de impedimento mecânico do solo em sistemas agrícolas com a soja. Londrina, Embrapa Soja, 1999. 58p. (Embrapa Soja. Circular Técnica, 23)

VINCENT, J.M. A manual for the practical study of rootnodule bacteria. Oxford, Blackwell Scientific Publication, 1970. $164 \mathrm{p}$.

Wiethölter, S. Calagem no Brasil. Passo Fundo, Embrapa Trigo, 2000. 104p. (Embrapa Trigo. Documentos, 22) 